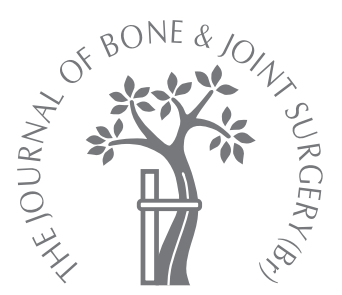

A. W. Blom,

L. Astle,

J. Loveridge,

I. D. Learmonth

From the Avon

Orthopaedic Centre, Bristol, England

A. W. Blom, PhD, FRCS (Trauma \& Orth), Locum Consultant

L. Astle, MRCS, Specialist Registrar

J. Loveridge, MRCS

Senior House Officer

I. D. Learmonth, FRCS, FCS

(SA), Professor and Head of

Department

Avon Orthopaedic Centre,

Southmead Hospital

Westbury-on-Trym, Bristol

BS10 5NB, UK.

Correspondence should be sent to Mr A. W. Blom;

e-mail: blocat@msn.com

C2005 British Editorial

Society of Bone and

Joint Surgery

doi:10.1302/0301-620X.87B12. $16349 \$ 2.00$

$J$ Bone Joint Surg [Br]

2005;87-B:1636-8.

Received 31 January 2005

Accepted after revision

9 August 2005

\title{
Revision of an acetabular liner has a high risk of dislocation
}

Polyethylene liners of modular acetabular components wear sometimes need to be replaced, despite the metal shell being well fixed. Replacing the liner is a relatively simple procedure, but very little is known of the outcome of revision. We prospectively followed up 1126 Harris-Galante I metal-backed, uncemented components for between nine and 19 years. We found $38(3.4 \%)$ liners of 1126 acetabular components wore and required revision. These revisions were then followed up for a mean of 4.8 years. The rate of dislocation was $\mathbf{2 8 . 9 \%}$. Nine of the dislocations occurred once and two were recurrent.

The overall secondary revision rate was three of 38 total hip replacements $(7.9 \%)$ at a mean follow-up of 4.8 years. This gives a $92.1 \%$ survivorship ( 35 of 38 ) at under five years. In isolated revision of a liner, we had a complication rate of $23 \%$ (three of 13). In revision of a liner combined with revision of the femoral stem, there was a complication rate of $48 \%$ (12 of 25). We discuss possible reasons for the high dislocation rates.

Leaving the well-fixed acetabular shell in situ leads to an increased risk of instability. However, this needs to be balanced against the otherwise low complication rate for revision of the liner. Patients should be consented accordingly.

Polyethylene liners of modular acetabular components wear and sometimes need to be replaced, despite the metal shell being well fixed. Replacing the liner is a relatively simple procedure, but very little is known of the outcome of revision. We revised 38 worn polyethylene liners in Harris-Galante I acetabular components (HGP 1, Zimmer, Swindon, UK).

\section{Patients and Methods}

Between 1986 and 1996, 1126 Harris-Galante I metal-backed, uncemented cups were inserted at the Winford Orthopaedic Hospital (1986 to 1992) and the Avon Orthopaedic Centre (1992 to 1996) in Bristol. All the patients were reviewed annually, both clinically and radiographically (anteroposterior and lateral radiographs). Polyethylene acetabular liners which showed signs of excessive wear were revised by simple exchange. At the time of exchange the locking tines were checked to make sure that they were not fractured or bent. The new liners were not cemented into place. If the stem showed signs of aseptic loosening and osteolysis, it was also revised. All patients were then reviewed annually and complications were noted.

\section{Results}

Between nine and 19 years, we found of 1126 acetabular components, $38(3.4 \%)$ liners in 34 patients wore and required revision. At primary surgery, 148 patients had 165 32-mm femoral heads. Of these 165 total hip arthroplasties $17(10.3 \%)$ required revision of the liner. There were 961 patients who had 22-mm or $28-\mathrm{mm}$ femoral heads implanted at primary surgery. Of these 961 total hip arthroplasties, $21(2.2 \%)$ required revision of the liner.

The mean time from primary surgery to revision was 10.2 years (3 to 17). At revision 13 hips had only the liner revised. Because 25 hips had aseptic loosening of the femoral component, both the acetabular liner and the femoral component were revised. None of the 38 cases required revision of the acetabular shell as there was no noticeable osteolysis. The modular femoral heads were exchanged for heads with the same offset. The mean follow-up after revision was 4.8 years (20 to 141 months).

For the group that had only revision of the acetabular liner, the complications are outlined in Table I. For the group that had both the acetabular liner and the femoral component revised, the complications are outlined in Table II. 
Table I. Complications following isolated revision of the liner $(n=13)$

\begin{tabular}{ll}
\hline Complication & Number (\%) \\
\hline Dislocations & $2(15.4)$ \\
Wear of new liner & $1(7.7)$ \\
Aseptic loosening of acetabular component & $0(0)$ \\
Aseptic loosening of femoral component & $0(0)$ \\
\hline
\end{tabular}

Table II. Complications following revision of the acetabular liner and femoral component $(n=25)$

\begin{tabular}{ll}
\hline Complication & Number (\%) \\
\hline Dislocations & $9(36)$ \\
Wear of new liner & $0(0)$ \\
Aseptic loosening of acetabular component & $0(0)$ \\
Aseptic loosening of femoral component & $2(8)$ \\
Periprosthetic fracture & $1(4)$ \\
\hline
\end{tabular}

The combined rate of dislocation for the two groups was $29 \%$ ( 11 of 38 cases). Of the dislocations, nine ( $82 \%$ ) were single and two were recurrent. One patient dislocated twice and another dislocated eight times.

The overall secondary revision rate was three of 38 total hip replacements $(7.9 \%)$ at a mean follow-up of 4.8 years, giving a $92.1 \%$ survivorship at just under five years. One patient with recurrent dislocation, one with aseptic loosening of the femoral component and one with a periprosthetic fracture were revised. Where the direction of dislocation was noted at the time of reduction, it was anterior.

\section{Discussion}

Revision of an acetabular liner is not a benign procedure, even if the risk of requiring a further revision is acceptable. In isolated revision of a liner we had a complication rate of $23 \%$ (three of 13 ). Where revision of a liner was combined with revision of the femoral component, this complication rose to $48 \%$ (12 of 25 ). Boucher et $\mathrm{al}^{1}$ reported a $25 \%$ dislocation rate with isolated revision of a polyethylene liner. Earll et $\mathrm{al}^{2}$ reported a $55 \%$ dislocation rate after treating instability by revision of a liner. However O'Brien et $\mathrm{al}^{3}$ and Lachiewicz, Soileau and Ellis ${ }^{4}$ reported lower dislocation rates of zero and $18 \%$, respectively. Our dislocation rate for isolated revision of an acetabular liner $(15 \%)$ compares favourably with these reports.

The majority of complications were dislocations. Fortunately, most of these were single episodes. The audited dislocation rate after revision hip arthroplasty in our unit over the same time period, and performed by the same surgeons as in this study, was 23 of 284 cases $(8.1 \%)$.

It is interesting to postulate the causes for the high dislocation rate. O'Brien et $\mathrm{al}^{3}$ believe that using the direct lateral approach ${ }^{5}$ accounted for their low dislocation rate. The Omega lateral approach ${ }^{6}$ was used in this study, but could not match the excellent results achieved by O'Brien et $\mathrm{al}^{3}{ }^{3}$ The Omega approach is a direct lateral approach with a lateral skin incision over the greater trochanter, and the fascia lata split in line with the skin incision. An omega-shaped incision is then commenced distally, some 2 to $3 \mathrm{~cm}$ into vastus lateralis posteriorly, is carried around the anterior border of the greater trochanter while remaining in the thick tendo-aponeurotic tissue, to extend posteriorly along the superior border of the greater trochanter down to the posterior attachment of the tendon of gluteus medius. The proximal limb of the omega extends $1 \mathrm{~cm}$ above the tip of the greater trochanter, behind the gluteus medius tendon.

The risk of dislocation after revision hip surgery when the acetabular component is revised is high $(15 \%$ to $18 \%),{ }^{7-9}$ but not as high as the risk after revision of a liner with retention of the acetabular shell. In revision surgery scar tissue is divided and sometimes removed. This leads to instability in the short term, most probably due to a lack of tissue tension. When the acetabular component is revised, a new position of optimum stability can be found by the operating surgeon, and the components implanted accordingly. If the acetabular component is not revised, this is not possible. For this reason, we believe that leaving the wellfixed acetabular shell in situ leads to an increased risk of instability. However, this needs to be balanced against the otherwise low complication rate for revision of a liner. Patients should be consented accordingly.

We would recommend a number of intra-operative measures to address problems of tissue tension and stability, as well as post-operative measures to reduce the risk of dislocation. Higher offset femoral necks and appropriate tensioning of the soft tissues, by reefing if necessary, should be considered in all cases. Liners with elevated rims should be used with the rim placed according to the position of maximum stability, in this series, an anteriorly-placed rim may have reduced the anterior dislocations. It is possible to address acetabular anteversion by cementing a liner into the well-fixed acetabular component. An advantage of exchange of a liner in a modular system is that the femoral head size can be increased with an acetabular liner of correspondingly increased inner diameter, thereby increasing the primary arc of motion. Sultan et $\mathrm{al}^{10}$ demonstrated that a $15^{\circ}$ elevated liner increased the primary arc of movement by $8.9^{\circ}$. They also showed that an increase in femoral head diameter from 28 to $32 \mathrm{~mm}$ increased the primary arc of movement by $8.9^{\circ} .{ }^{10}$

Surgeons should consider the routine post-operative use of additional measures such as knee orthoses or hip spicas in order to decrease the risk of instability.

No benefits in any form have been received or will be received from a commercial party releated directly or indirectly to the subject of this article.

\section{References}

1. Boucher HR, Lynch C, Young AM, Engh CA, Engh C Sr. Dislocation after polyethylene liner exchange in total hip arthroplasty. J Arthroplasty 2003;18:654-7.

2. Earll MD, Fehring TK, Griffin WL, et al. Success rate of modular component exchange for the treatment of an unstable total hip arthroplasty. J Arthroplasty 2002; 17:864-9. 
3. O'Brien JJ, Burnett RS, McCalden RW, et al. Isolated liner exchange in revision total hip arthroplasty: clinical results using the direct lateral surgical approach. J Arthroplasty 2004:4:414-23.

4. Lachiewicz PF, Soileau E, Ellis J. Modular revision for recurrent dislocation of primary and revision total hip arthroplasty. J Arthroplasty 2004;19:424-9.

5. Hardinge K. The direct lateral approach to the hip. J Bone Joint Surg [Br] 1982;64-B: $17-19$.

6. Learmonth ID, Allen PE. The omega lateral approach to the hip. J Bone Joint Surg [Br] 1996;78-B:559-61.
7. Paterno SA, Lachiewicz PF, Kelley SS. The influence of patient-related factors and the position of the acetabular component on the rate of dislocation after total hip replacement. J Bone Joint Surg [Am] 1997;79-A:1202-10.

8. Whiteside A. Major femoral bone loss in revision total hip arthroplasty treated with tapered, porous-coated stems. Clin Orthop 2004;9:222-6.

9. Goodman S, Pressman A, Saastamoinen H, Gross A. Modified sliding trochanteric osteotomy in revision total hip arthroplasty. J Arthroplasty 2004:8:1039-41.

10. Sultan PG, Tan V, Lai M, Garino JP. Independent contribution of elevanted-rim acetabular liner and femoral head size to the stability of total hip implants. J Arthroplasty 2002;17:289-92. 